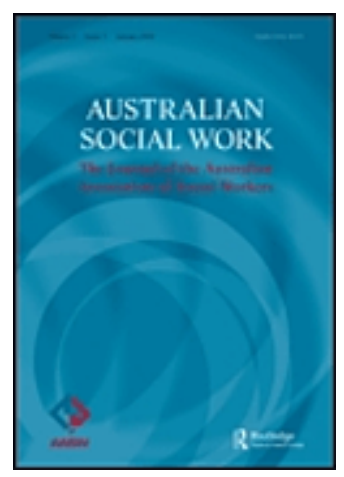

\title{
Overcoming future professionals' fear of digital storytelling
}

\begin{tabular}{|r|l|}
\hline Journal: & Australian Social Work \\
\hline Manuscript ID & Draft \\
\hline Manuscript Type: & Article \\
\hline Keywords: & $\begin{array}{l}\text { Digital storytelling, Social media, Human services and social work, } \\
\text { Higher education, Pedagogy of discomfort }\end{array}$ \\
\hline \multicolumn{2}{|l}{} \\
\hline
\end{tabular}

\section{SCHOLARONE Manuscripts}




\title{
Title:
}

Overcoming future professionals' fear of digital storytelling

\begin{abstract}
:
Digital storytelling assessments at university can develop emerging human service and social workers' skills in contemporary social media production and related advocacy. Despite growing interest in digital storytelling in these disciplines, there is little support for developing the technical sides of the practice. This article shares key learnings from an Australian teaching and learning project used to develop a digital storytelling module for non-filmmaker social work and human services students at university. Students across a range of courses undertook digital storytelling assessments using the module. A key finding was that students still experienced considerable fear but were able to turn that into significant personal and professional development. This article explores these and other key learnings from the project and offers tips to others wishing to implement digital storytelling.
\end{abstract}

\section{Implications:}

- Digital storytelling is a contemporary skill for human services and social work professionals. Emerging professionals studying at university often exhibit fear and resistance to the technical aspects of digital storytelling.

- $\quad$ Our project developed and evaluated a technical module that supported students to make digital stories over six weeks.

- Although students still experienced fear and apprehension, a majority experienced transformation and developed confidence and skills in digital storytelling after only one assignment.

\section{Keywords:}


- Digital storytelling

- Human services and social work

- Higher education

- $\quad$ Social media

- $\quad$ Pedagogy of discomfort 


\section{Introduction}

Over the past thirty years, digital storytelling has become a key aspect of social media production, education, and advocacy for social change. Digital storytelling's original aims were to amplify the voices of those who experienced social marginalisation. Over time, it has become a key element of service user engagement, deep learning, and anti-oppressive "listening" campaigns in government, non-government, and not-for-profit organisations such as hospitals, universities, and international advocacy networks such as Handicap International's Ban Advocates program (Gachago and Cronje, 2015; Lewis and Matthews, 2017; Matthews and Sunderland, 2017). So-called "classic" digital storytelling, as conceived by the Center for Digital Storytelling (now referred to as the Story Center) at the University of Berkeley, combined the art of verbal storytelling through recorded voice with still images, sounds, and film to create 3-4 minute multi-media videos that conveyed personal or community stories (Lambert, 2013, 2017). Digital storytelling emerged concurrently with the Internet and was part of citizen-led content creation movements (Lambert, 2017).

Contemporary digital storytelling and social media platforms have moved beyond the Berkeley model to now broadly involve "life-story telling in a variety of mediated forms deployed to prompt social change" (Sunderland and Matthews, 2019). Recent research on digital storytelling emphasises that, although there is potential to interrupt dynamics of silencing and social exclusion through digital storytelling, more attention is needed to the politics of listening to and applying those stories in social change. Researchers are examining how powerful elites are listening - or not - to digital stories and what the effects of that listening are on social, cultural, and political institutions (Dreher, 2010; Matthews and Sunderland, 2017; Wheeler, 2018). Hence, we observe that digital storytelling and related 
contemporary media practices are key considerations for contemporary social work and human services teachers, researchers, and practitioners.

This paper reports on the outcomes of a teaching and learning grant at

, Australia that involved designing and evaluating a digital storytelling technical support module for non-filmmaker human services and social work students. The purpose of the module was to provide introductory technical guidance on how to make a digital story. The project originated after several course convenors in our School found that non-filmmaker students exhibited considerable fear of digital storytelling due to its novelty for them. This was particularly the case for mature aged students who had not previously used filmmaking equipment, editing software, or online sharing platforms such as YouTube or Vimeo.

This paper outlines the background and rationale for using digital storytelling assessments in human services and social work education. We then describe the processes via which the module was developed and evaluated and share the main findings of the evaluation. We conclude by discussing the major learnings and tips that emerged from the project.

\section{Background}

Digital storytelling has been used internationally in health and human services to promote "voice" for populations who have been systematically marginalised. This has included activities as diverse as: urban planning and regeneration (Estrada-Grajales, Foth, \& Mitchell, 2018; Wheeler, 2018); rural education research and planning (Staley, 2017); dementia care planning and evaluation (Capstick and Ludwin, 2015); and hospital policy making and service planning (Hardy and Sumner, 2018). Digital storytelling has been used for therapeutic intervention in positive identity development (Anderson and Mack, 2019) and narrative 
therapy (Anderson and Wallace, 2015; Thumim, 2017; Shea, 2018). Lambert (2013) emphasised that digital storytelling and listening can result in community-building between participants.

Social work and human services researchers have explored digital storytelling across higher education (Anderson, 2017; Goldingay, Epstein, \& Taylor, 2018; MacDermott, Harkin-MacDermott, \& Wylie, 2019; Marín, Tur, \& Challinor, 2018), advocacy (Lenette, Cox, \& Brough, 2015; Matthews and Sunderland, 2017), and therapeutic contexts (Anderson and Mack, 2019; Anderson and Wallace, 2015; Beltrán \& Begun, 2014). Lenette, Cox, and Brough (2015, p. 988) emphasised digital storytelling as a professional "social work tool” for client self-representation, countering dominant narratives, enhancing advocacy, and helping workers to understand client needs. Despite those growing roles for digital storytelling in human services and social work, there is scarce literature on how to prepare emerging human services and social work professionals for the technical sides of digital storytelling.

A search of digital storytelling in other disciplines indicated that there is a small collection of literature describing approaches to preparing students for the technical sides of digital storytelling. These range from full courses in media production to one on one support outside of class. Blithe, Carrera and Medaille (2015), for example, incorporated five hands on workshops into their cross-cultural communications courses. These sessions took students step by step through a technical process under the guidance of a media specialist or librarian. Students were also supported outside of class with extensive one on one support by the course instructor. Within a communication degree, Francis (2014) limited in class skills development to story and structural elements, requiring students to enrol in an additional oncampus production course to gain the requisite technical skills. Due to the need to satisfy Australian Association of Social Workers accreditation requirements and the trimester model 
at our university - which had shortened the number of weeks in each teaching period - we had limited time that could be allocated to skills development within individual courses or degree programs. We hence chose to develop a bespoke digital storytelling technical module in collaboration with the that would cover elements of story construction, filming, and editing. Students could then participate in 30-60 minute assessment support sessions that referred to the module in class and draw on the module 24 hours a day in their own time.

\section{Methodology}

The project team - including participating course convenors (including Authors 1 and 2), a digital storytelling and film specialist (Author 3), and blended learning advisers - generated a pilot digital storytelling module in several stages. First, the team agreed on the requirements for the digital storytelling module based on convenors' and advisers' previous experiences in digital storytelling assessments. Next, Author 3 drafted a "project brief" that summarised the key aims and functions of a digital storytelling module that would support digital storytelling assessments for non-filmmaker students across the university. Our intent was that the module would be applicable across all disciplines. Following that, Author 3 researched appropriate software and editing approaches for beginner filmmakers which he supplemented with professional experience facilitating digital storytelling in community settings.

Author 3 drafted a pilot digital storytelling module in PDF form that was circulated to the project team and advisory group for feedback (see Appendix 1 for excerpt). The content was arranged week by week over six weeks, progressing from Settling In to Engagement, Story, Editing, Finishing and Uploading, with two weeks allocated to Editing. Each week's stage was presented on a single page providing context, tips and resources. Headings included Overview; Description; Marking criteria; Student Digital Storytelling Exemplars; 
Getting Started; Ethics; Gathering Impressions; Shooting Tips; Helpful Videos; Making Sense of Your Impressions; Storytelling Tips; Editing your story; A Picture is Worth a Thousand Words; Editing Tutorials; Finishing up; and Uploading. The PDF was available on participating course BlackBoard sites for students alongside course-specific task descriptions and assessment criteria. Teaching staff guided students through the PDF in on campus classes and online tutorials. All students had access to online discussion boards for assessment questions and discussion.

\section{Module evaluation}

A mixed methods approach was used to evaluate the module and its pilot implementation as outlined below.

\section{Recruitment and participation}

Author 1 used an all-staff meeting to call for participation in the project from convenors who were interested in using digital storytelling in human services and social work courses. We realised that students may feel overwhelmed if digital storytelling was introduced in more than one of their courses at a time. Hence, we selected courses that were spread across year levels including: First Australians and Social Justice (undergraduate second year); Field Placement (undergraduate third year); and First Australians and Social Justice (Advanced master level). The number of students enrolled in each course were: First Australians and Social Justice $(n=205)$; Field Placement $(n=28)$; and First Australians and Social Justice Advanced $(n=60)$.

All students completed a digital storytelling assessment using the pilot PDF module and were invited to participate in a survey and focus group to evaluate the module. Students across three campuses were approached via email announcements as part of this recruitment 
including: online only students who were studying externally across Australia; students at the university's largest campus located on the urban ; and students enrolled at the university's smallest campus located in ex-urban

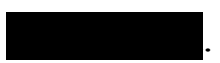

A total of 91 students completed the surveys which represents a response rate of 31 percent across the three courses. Of those students who participated in the survey, 23 percent $(n=21)$ were First Australians and Social Justice Advanced students, 51.6 percent $(n=47)$ were First Australians and Social Justice undergraduate students, and 19.8 percent $(n=18)$ were Field Placement students. This is reflective of the student enrolment numbers in each course. The remaining five students did not correctly enter their course code. Of the 91 students who participated, 27.5 percent $(n=25)$ were studying online, $16.5(n=15)$ percent were studying at the campus, and 56 percent $(n=51)$ were studying at the

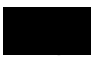
campus. Two focus groups were conducted with a total of 12 students across the two groups. Of these, six were online First Australians and Social Justice masters and undergraduate students and six were $\_$campus Field Placement undergraduate students.

\section{Ethics}

Ethical approval for the research evaluation was granted by the Human Research Ethics Committee. Students were offered a written participant information and consent package via email announcements and invited to participate in the research.

\section{Data collection}

Data collection included open and closed answer surveys and two focus groups. The surveys included open and closed answer questions delivered via Google Forms (online) and printed surveys. Information on the students' course code, campus of study, and number of hours 
spent on the digital storytelling assessment was collected. Students were asked to complete a series of closed answer questions that required them to self-rate their digital storytelling skills, knowledge, and experience on a five point scale from poor to excellent. Examples of those questions included: How would you rate your level of digital storytelling skill/knowledge at the start of this course?; How would you rate your level of digital storytelling skill/knowledge at the end of this course?; and How would you rate the contribution of the How to make a Digital Story PDF to your skill/knowledge?

Students were asked to rate their level of agreement to the following questions using a five point scale ranging from strongly disagree to strongly agree: The assessment was challenging; The assessment was stimulating; The assessment was achievable; The How to make a digital story PDF resource was useful; In class support activities helped me to understand the digital story assessment; In class support activities helped me to complete the digital story assessment; I can see the value in using this kind of assessment in this course; I would like to do more digital story assessments in my courses; I prefer digital story assessments over essay assessments; and The task description for this assignment was clear.

The surveys concluded with open ended questions such as: What aspects of the How to Make a Digital Story PDF were most useful or valuable?; How could we improve the How to Make a Digital Story PDF to make it more helpful for students in the future?; What other support activities (e.g. in class or online) could we offer to help students with digital storytelling assessments?; and What, if any, forms of growth and reflection were enabled by completing the digital story instead of a written reflection?.

The first focus group was conducted on the campus with Field Placement students and included: two female study abroad students; one male and one female domestic student with English as a second language; and one male and one female domestic student. 
The second focus group was conducted online via BlackBoard Collaborate with First Australians and Social Justice (Advanced) and undergraduate students due to the diverse geographical locations of students who had volunteered to participate. All participants in that focus group were female domestic students who were studying online.

Focus groups included the following questions: Have you completed a digital story before?; What three words come to mind when you think of the digital storytelling assessment overall?; How did you use the module that was provided?; Which additional resources did you need to find for yourself outside of what was provided in the course? What were the most rewarding or challenging aspects of doing this digital story assessment in your experience?; What did you learn about your professional identity and practice framework while completing the digital story?; Do you think future students should complete the digital story?; What additional resources should be provided?; How do you think you would've learned differently if you were writing down a reflection, as opposed to using the digital story format?

\section{Data analysis}

Descriptive statistics and figures from survey data were generated using Microsoft Excel and SPSS. Data-driven coding and thematic analysis of the open ended survey questions and focus group data was conducted collaboratively and cross-checked by Authors 1 and 2 using NVIVO software (DeCuir-Gunby, Marshall, and McCulloch, 2011; Ryan and Bernard, 2003). Focus group recordings were professionally transcribed prior to coding and analysis.

\section{Results}

Data indicated that a majority of students were positive about digital storytelling, rapidly gained confidence, and found the pilot module and other support activities to be sufficient. 
Students did, however, experience significant fear in relation to the assessment and offered suggestions for additional support that were taken up in later versions of the module. Most students had not undertaken digital storytelling prior to this project. Notably, students did not report significant problems with using cameras or phones to capture original media for their story. Some found it particularly enabling that they could shoot and edit their story on their smartphone or tablet.

Students spent varying amounts of time on the digital storytelling assignments. Survey responses indicated that 8.2 percent spent more than 40 hours on the digital story, 12.3 percent spent 30-40 hours, 16.4 percent spent 20-30 hours, 26 percent spent 15-20 hours, 16.4 percent spent 10-15 hours, 15.1 percent spent 5-10 hours, and 5.6 percent spent up to five hours. This indicates that a majority of students (63.1 percent) spent less than 20 hours on the digital story. Clear themes of personal development and fear emerged from the qualitative data and students referred to ways that they would use digital storytelling as part of their practice toolkit.

\section{Students experienced fear but rapidly gained confidence}

The research confirmed that a significant number of students initially experienced fear and anxiety but were largely able to overcome that fear to develop confidence within a relatively short time. Sources of fear included: fear of personal exposure when their stories were posted online; fear of hearing their own voice recorded; fear of the assignment being unfairly marked by prioritising technical skill or creativity; and fear of doing something new with technology, in particular editing their story using software and uploading it to YouTube or Vimeo. Mature aged students in particular experienced fear of learning new technical skills. 
Several students recognised a very personal or emotional component in their initial

resistance to the assessment. In the words of one student:

Mine [fear] was definitely more around the self-exposure and that part of it. You putting yourself out there a bit and I found that really difficult. I spent a lot of time thinking about it, waking up in the middle of the night and changing things. And yeah, that was probably a good part of it though, I think it was good for me.

And another:

I guess my biggest struggle was that I'm technologically challenged and felt from the outset like this would impair my mark. It was an emotional restriction I had to overcome. In the end, I just gave the editing my best shot... and I hope it was enough to get me over the line [to pass the course overall].

That theme of overcoming fear to achieve a positive learning outcome is confirmed in other student accounts such as:

My 20-year-old was very helpful in that I went, "Oh, my gosh. What do I do?" Because when he was younger, he used to like making little movies. He said, "iMovie's on your laptop, Mum. You'll be fine." I'm like, "Great. Thanks."

And I was, to be fair, I was.

And:

... apart from the growth and changes in thinking and reflection that I experienced, I also surprised myself by actually making the movie, and I'm someone who can't even operate their own iPod.

And:

Initially I was daunted as I had not previously used any film editing software but actually found it surprisingly easy to learn the basics!

Further, as reflected in Figure 1, students' self-rating of their digital storytelling skills and knowledge improved greatly from the start to finish of the assessment. This indicated that many students experienced positive outcomes of overcoming fear and developing knowledge, confidence, and skills.

\{insert figure 1 approximately here\} 
Seven students shared negative accounts of their experience. These included statements such as: "the task was daunting and sometimes I think the PDF added more to the stress rather than help" and "Skills learned could not be incorporated in any other course assignment, or in future employment in the Human Services industry”. Accessing and using appropriate editing software appeared to be frustrating for some students, even though free and easy to use software had been suggested in the PDF module. One mature aged online student from a non-English speaking background felt that none of the support that had been provided was effective. In her words:

I'm still stuck, and I know I might be a bit of a party pooper here, but I'm still stuck on the technology part that scared me, took so much energy out of me. So I think the whole idea of the digital story is great or the whole idea of expressing yourself through words and videos or photos, I still think that if I would've got the same assignment, just put your photos and talk about them in the PowerPoint, for example, from a technology perspective would've taken much less. I wouldn't be having such anxiety, but again, that's personal. It might be age related. It might be just I'm not technology savvy, or I'm just afraid of it.

That student indicated during the focus group that one-to-one mentoring was the only thing that could have made her journey comfortable. Notably, despite her extreme level of distress, the student indicated that she felt confident to make digital stories in the future after completing only one digital storytelling assessment.

Students who regarded their knowledge and skills to be poor or fair at the beginning of the course still found the assignment to be achievable as reflected in Figure 2. When asked to respond to the statement "I would like to do more digital story assessments in the future", 57.6 percent of students agreed or strongly agreed, 18.8 percent were neutral, and 13.8 disagreed or strongly disagreed. When asked to respond to the statement "I prefer digital story assessments over essay assessments", 52.5 percent of students agreed or strongly agreed, 20 percent were neutral, and 18.8 percent disagreed or strongly disagreed. This 
indicated that a strong majority of students were in favour of, or neutral about, the continued use of digital storytelling as part of their education.

\{insert figure 2 approximately here\}

The research indicated that students could adapt their new skills and knowledge for professional practice. For example, one student reflected: "I am developing a similar idea with clients who have intellectual disabilities as I'm interested to see if in developing their story there is a building of empathy between the client and their support staff'. Students could also recognise the need for contemporary skills such as digital storytelling and its strong connection to professional values such as inclusion and social justice. As one student reflected:

I also think that it's fairly contemporary in there, that it's the modern way of engaging. And when we go into practice, perhaps this might be something that we can use... I also think that it's good for people who can't express themselves or have more difficulties expressing themselves with the written word. So it's encompassing all abilities...

Hence, despite some important negative experiences, students largely overcame their fears and developed confidence, knowledge, and applicable professional skills.

\section{What helped students to make digital stories?}

The PDF module helped a majority of students to make digital stories. A total of 60 percent of students who completed the surveys agreed or strongly agreed that the pilot module was a helpful resource for completing digital stories. Of the remaining students, 23.8 percent were neutral, 5 percent disagreed, and 2.5 percent strongly disagreed. We note that approximately 18.7 percent $(n=17)$ of students did not use the module due to previous experience in digital storytelling or help from external sources which may account for the percentage of neutral responses to this question. 
Figure 3 is an NVIVO 11 hierarchy chart illustrating support that was helpful to students. A majority of students expressed that the support provided between the module and in class activities was sufficient. Students found that the module's suggested timeline for developing the digital story, examples of previous student stories, and step-by-step process were the most helpful as reflected in quotations such as: "The video examples and the way it was broken down step by step made it less overwhelming" and "The PDF was organised very well it broke down the assignment week by week and gave resources for each step of the way". Previous examples of student digital stories were also a highly valued resource as reflected in this focus group discussion:

Student 1: we had links to previous students' digital stories, which, I found that really helpful too. Just watching and going, "Oh, okay. I get it now." Everyone obviously had a different take on what to do, but just watching that, it was really reassuring as well.

Student 2: I found that helpful too, yeah, seeing how other students had approached it.

Student 3: I agree.

Student 4: I think I do as well. I liked that you could see how different the... the completely different ways people approached it. I think that was really good too.

To a lesser extent, students identified that in class support, teaching team receptiveness to questions, online tutorials suggested in the module (e.g. via YouTube), and online Collaborate sessions were valued resources as reflected in Figure 3. This indicates that the module was the primary form of support favoured by students.

\{insert figure 3 approximately here\}

\section{What other support did students request?}

Students indicated that additional support could be provided in the following areas: IT skills and knowledge and mentoring with a focus on uploading stories to YouTube and learning 
editing software; additional classes and student collaboration groups; more examples of previous student stories; changes to the assignment task descriptions to clarify requirements; online resources such as YouTube tutorials; one-to-one support; Q\&A drop-in sessions; and other experiences outside of class such as guided walks. Figure 4 provides a visualisation of the number of student references to each of the additional supports.

\{insert figure 4 approximately here\}

\section{Discussion}

This teaching and learning project found that human services and social work students are clearly able to develop knowledge, skills, and confidence in digital storytelling in relatively short timeframes and despite significant initial fear and apprehension. Consonant with previous research by Lenette, Cox, and Brough (2015) the project showed that students are able to apply digital storytelling in contemporary practice and make connections to social work and human services values such as inclusion and social justice. Even students who exhibited extreme anxiety during this project felt confident and motivated to undertake future digital storytelling after one assignment.

We were surprised about the degree of student anxiety that remained even after the module was introduced. At the outset of the project, we had wanted to greatly minimise - or eradicate - student fears and thought that providing a bespoke technical module would achieve that aim. After conducting the research, we realised that fear and apprehension are perhaps unavoidable and potentially productive elements of students' experiences. Digital storytelling was placing students outside of their comfort zone and initiating a 'pedagogy of discomfort' which is a known outcome of digital storytelling in social work and other disciplines (Gresham, 2014; Thomas and Marks, 2014). Hence, rather than attempting to 
eradicate student fears, we resolved at the conclusion of the project to normalise them and encourage students to seek a transformative learning experience.

When fear is an acknowledged part of the teaching and learning process, it is important to find ways of supporting "growth of self when students find themselves in a place of discomfort" (Munroe, 2016). The Blended Learning Adviser for the project, Mary-Ann Shuker, suggested additional resources for supporting students. Mary-Ann gave tips such as: if you're nervous about making the story get in as early as possible and "play" with the software. She provided a TED talk to share with students that emphasised the value of adopting a "learning mindset" when faced with challenges (see Briceno, 2012). Students who participated in our research also indicated that in-class and peer group connection outside of class are important sources of support, as are lecturers who are open to answering questions. Although we tried to find ways to resource one to one mentoring and technical support in class time - for example by hiring Film School senior students as tutors - we were unable to offer that option. We opted, instead, to have a one hour in class peer mentoring sessions in the week prior to submission for all students where confident students were paired with unconfident students to go through their digital story. If time allowed, students were also asked to give one another feedback on draft stories using the assessment marking criteria.

Both online and on campus students offered peer support and shared ideas with students who were struggling. In some cases, students asked staff if they could submit privately rather than via a class discussion board. After marking the digital stories, it was clear that students often shared profoundly personal stories which justified their request for private submission. A student who had initially refused to complete the digital story came to a teacher in the final class of trimester and said that although she had hated the idea of the digital story, the end product allowed all of her emotions and feelings which she could not 
write on paper to be expressed through art. We will explore those important aspects of digital storytelling in future publications.

Other changes to the final digital module included: detailed instructions on how to upload to YouTube and Vimeo; a section for anxious students including a TEDx talk on learning mindsets (Briceno, 2012); three mini-lectures by Author 3 that responded to research findings; and more examples of digital stories. The team also added a tip sheet for convenors for staff-only access which is included below.

\section{Limitations}

The project identified significant benefits of digital storytelling in promoting personal reflection and low cost experiential learning opportunities. It is beyond the scope of this paper to discuss those important outcomes but we will publish them elsewhere. A limitation of the research was that we did not gather demographic data such as age, gender, education, and socio-economic background that could be cross-tabulated with student responses.

\section{Tips for course convenors}

Tips emerging from the project are included below:

1. Start by going online and watching examples of digital stories from around the world.

2. Ask teachers from other courses for examples of student work they find compelling.

3. Make a simple digital story yourself and ask teaching team members to do the same.

4. Have students deconstruct good, bad and average exemplars in class so they can understand the assessment criteria and see first-hand what is effective. 
5. Offer students a recommended timeline for making their story with checkpoints and steps that they can achieve each week.

6. Emphasise that anxiety and fear can be normal reactions to learning new things and that "magic can happen" when we are outside of our comfort zones. Offer 1-2 activities for students who are experiencing fear to undertake immediately e.g. download the editing software and make a short digital story for family or friends. Encourage students to seek help with the software from family and friends. Many of our students successfully sought editing help from their school aged children.

7. Offer lots of examples of student stories and emphasise that diversity is key - students do not need to replicate other stories but can use them for inspiration.

8. It is important not to focus on the artistic or technical outcome. Digital stories are a way to communicate ideas that are not always easily reduced to words. The quality of those ideas and the story content are key to the exercise.

9. Students can be intimidated by technology. Key pressure points are getting started, moving the footage to the editing device, and uploading the video. It can simplify things for students to capture footage and edit it on the same device for example a smartphone or tablet. You can also do an exercise in the first couple of weeks of the semester where students upload a short video introduction of themselves.

10. Make sure you offer students flexibility in choosing editing software but have a list of free and easy to use options that you recommend and support students to use. Make sure that if students explore other options they know that some providers will try to lure them into paying a fee for editing software. 
11. Give weekly reminders and check-in regularly with students so that they stay on task. Videos take longer to produce than people realise. Resolve potential problems early and often.

12. Prepare a short procedure for students who do not have access to a camera or smartphone. How can they access one? By what date should they let you know?

13. Discuss options for adaptation directly with students with a disability. Specify a date in the teaching period by which students should contact you to request adaptation.

14. Encourage students to share their work with one another and get feedback. One option might be to make peer feedback a part of the assessment marking criteria.

15. Consider a private submission option for students with sensitive stories.

\section{Conclusion}

This project represented a collaborative, interdisciplinary approach to teaching and learning in human services and social work education across different years and levels of study at an Australian university. A particular focus of the project was to reduce student fear and anxiety around digital storytelling and other film-based assessments. At the conclusion of the project, team members realised that it is important to normalise the fear aspect of student experiences and provide support for students to move through that fear to achieve transformative learning and personal development outcomes. Future publications will focus on the reflective practice and experiential learning potential of digital storytelling in human services and social work education. A multimedia presentation of the team's work in this and other digital storytelling projects is available via the website at: 


\section{References}

Anderson, K. M. (2017). Let's Get Personal: Digital Stories for Transformational Learning in Social Work Students. In Digital Storytelling in Higher Education (pp. 73-89). Palgrave Macmillan, Cham.

Anderson, K. M., \& Mack, R. (2019). Digital storytelling: A narrative method for positive identity development in minority youth. Social Work with Groups, 42(1), 43-55.

Anderson, K., \& Wallace, B. (2015). Digital storytelling as a trauma narrative intervention for children exposed to domestic violence. Film and video-based therapy, 95-107.

Beltrán, R., \& Begun, S. (2014). 'It is Medicine' Narratives of Healing from the Aotearoa Digital Storytelling as Indigenous Media Project (ADSIMP). Psychology and Developing Societies, 26(2), 155-179.

Blithe, S. J., Carrera, W., \& Medaille, A. (2015). Stories of service-learning: Guidelines for increasing student engagement with digital storytelling. Journal of Library Innovation, 6(1), 60.

Briceno, E. (2012). The Power of belief: Mindset and success. TEDx Manhattan Beach. Available at https://www.youtube.com/watch? $\mathrm{v}=\mathrm{pN} 34 \mathrm{FNbOKXc}$.

Capstick A and Ludwin K (2015) Memories on film: digital storytelling with people in residential dementia care. AHRC Connected Communities Pararchive Conference, University of Leeds, 28 March 2015.

DeCuir-Gunby, J. T., Marshall, P. L., \& McCulloch, A. W. (2011). Developing and using a codebook for the analysis of interview data: An example from a professional development research project. Field Methods, 23(2), 136-155.

Dreher, T. (2010). Speaking up or being heard? Community media interventions and the politics of listening. Media, Culture \& Society, 32(1), 85-103.

Estrada-Grajales, C., Foth, M., \& Mitchell, P. (2018). Urban imaginaries of co-creating the city: Local activism meets citizen peer-production. Journal of Peer Production, (11).

Hardy, P., \& Sumner, T. (Eds.). (2018). Cultivating compassion: How digital storytelling is transforming healthcare. Springer.

Gachago, D., \& Cronje, F. (2015). When a story becomes more than just stoep-talk: digital counter-storytelling with pre-service teacher education students. In J, Condy (Ed.). Telling Stories Differently: Engaging 21st Century Students through Digital Storytelling, 117-130.

Goldingay, S., Epstein, S., \& Taylor, D. (2018). Simulating social work practice online with digital storytelling: challenges and opportunities. Social Work Education, 37(6), 790803.

Gresham, P. (2014). Fostering creativity through digital storytelling. Metaphor, (1), 47.

Lambert, J. (2013). Digital storytelling: Capturing lives, creating community. Routledge.

Lambert, J. (2017). The central role of practice in digital storytelling. In Digital Storytelling (pp. 21-26). Palgrave Macmillan, London.

Lenette, C., Cox, L., \& Brough, M. (2015). Digital Storytelling as a Social Work Tool: Learning from Ethnographic Research with Women from Refugee Backgrounds. British Journal of Social Work, 45(3), 1-28. doi:10.1093/bjsw/bct184.

Lewis, K., \& Matthews, N. (2017). The afterlife of Capture Wales: Digital Stories and their listening publics. In M. Dunford \& T. Jenkins (2017) (Eds), Digital Storytelling: Form and content (pp. 103-118). Palgrave Macmillan, London.

MacDermott, D., Harkin-MacDermott, C., \& Wylie, S. (2019). Before and After: Digital story telling with social work students in Northern Ireland. The Journal of Practice Teaching and Learning, 16(1), 51-67. 
Marín, V. I., Tur, G., \& Challinor, J. (2018). An interdisciplinary approach to the development of professional identity through digital storytelling in health and social care and teacher education. Social Work Education, 37(3), 396-412.

Matthews, N., \& Sunderland, N. (2017). Digital storytelling in health and social policy: Listening to marginalised voices. London, UK: Routledge.

Munroe, T. (2016). From College to University: What I learned navigating the child and youth care curriculum. Relational child and youth care practice, 29(3), 91-99.

Ryan, G. W., \& Bernard, H. R. (2003). Techniques to identify themes. Field methods, 15(1), 85-109.

Shea, M. (2018). The Sheffield Carers' Voices Project: Was It Therapeutic?. In Cultivating Compassion (pp. 213-227). Palgrave Macmillan, Cham.

Staley, B. (2017). Journeying beyond: Digital storytelling with rural youth. The Rural Educator, 38(2), pp. 23-34.

Sunderland, N., \& Matthews, N. (2019). Digital Storytelling and the Role of Meta-Orators in Institutional Listening. Storytelling, Self, Society, 15(1), 31-42.

Thomas, K. A., \& Marks, L. (2014). Action!: Student-generated videos in social work education. Journal of Technology in Human Services, 32(4), 254-274.

Thumim, N. (2017). Therapy, Democracy and the Creative Practice of Digital Storytelling. In M. Dunford \& T. Jenkins (2017) (Eds), Digital Storytelling: Form and content. Palgrave Macmillan, London. (pp. 229-240).

Wheeler, J. (2018). Troubling transformation: storytelling and political subjectivities in Cape Town, South Africa. Critical African Studies, 10(3), 329-344. 
Appendices

\section{Appendix 1: Page 1 of the pilot How to Make a Digital Story PDF module}

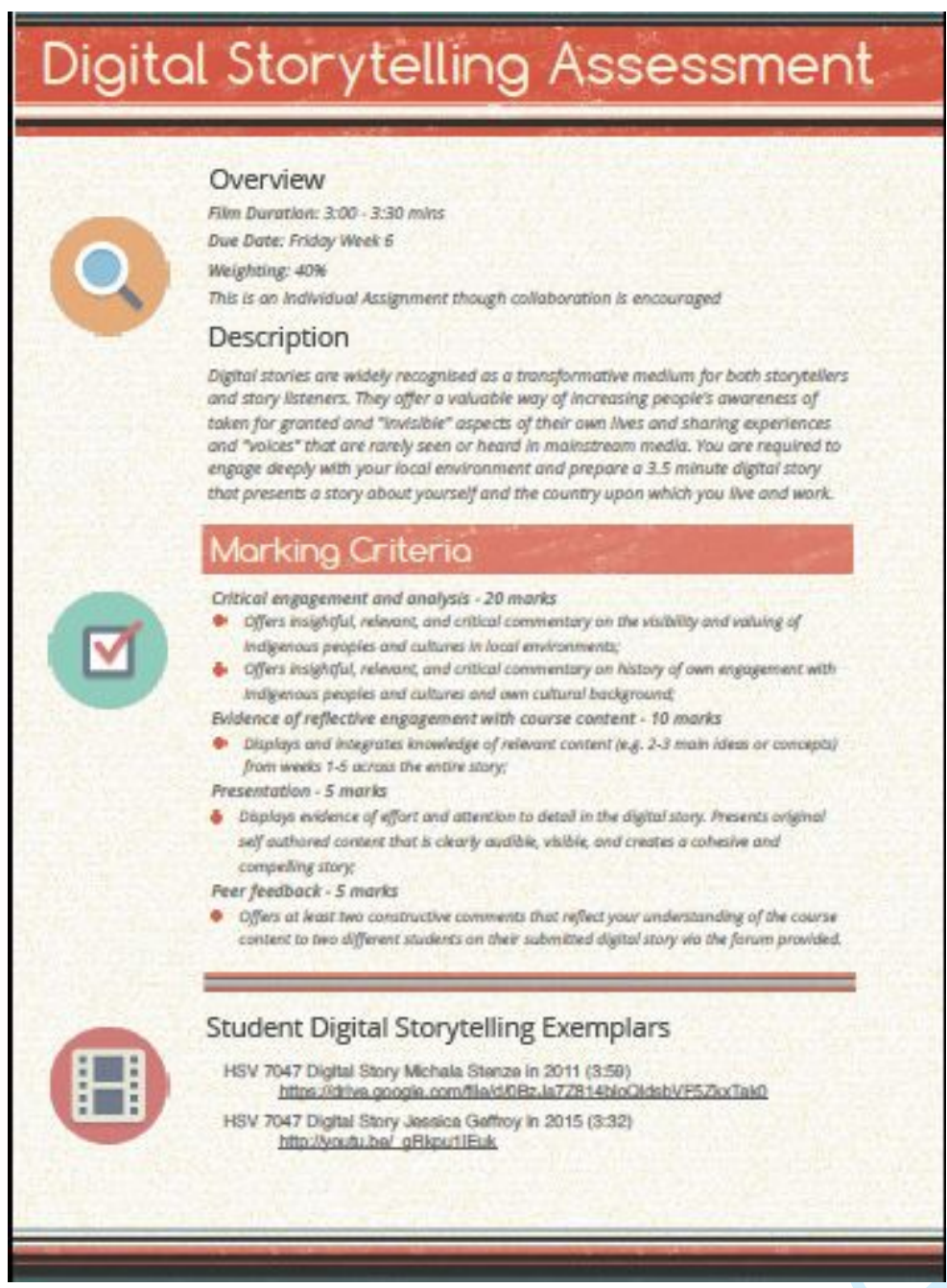




\section{Appendix 2: Screenshot of landing page for final Digital Stories Module}

\section{Digital Stories Module}

Select an icon to display the relevant information.

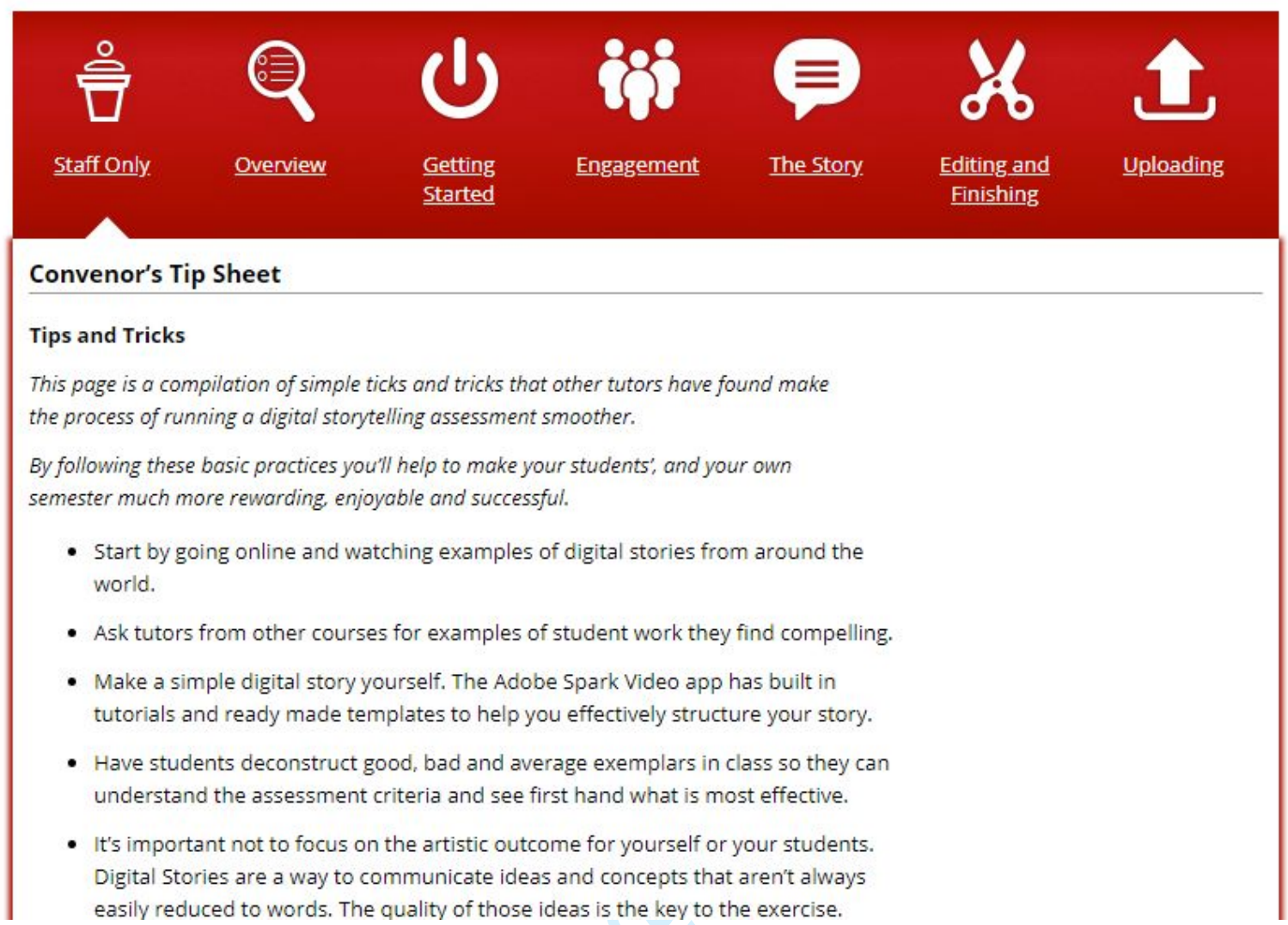


Figure 1 - Comparison of student self-rating of digital storytelling knowledge and skills

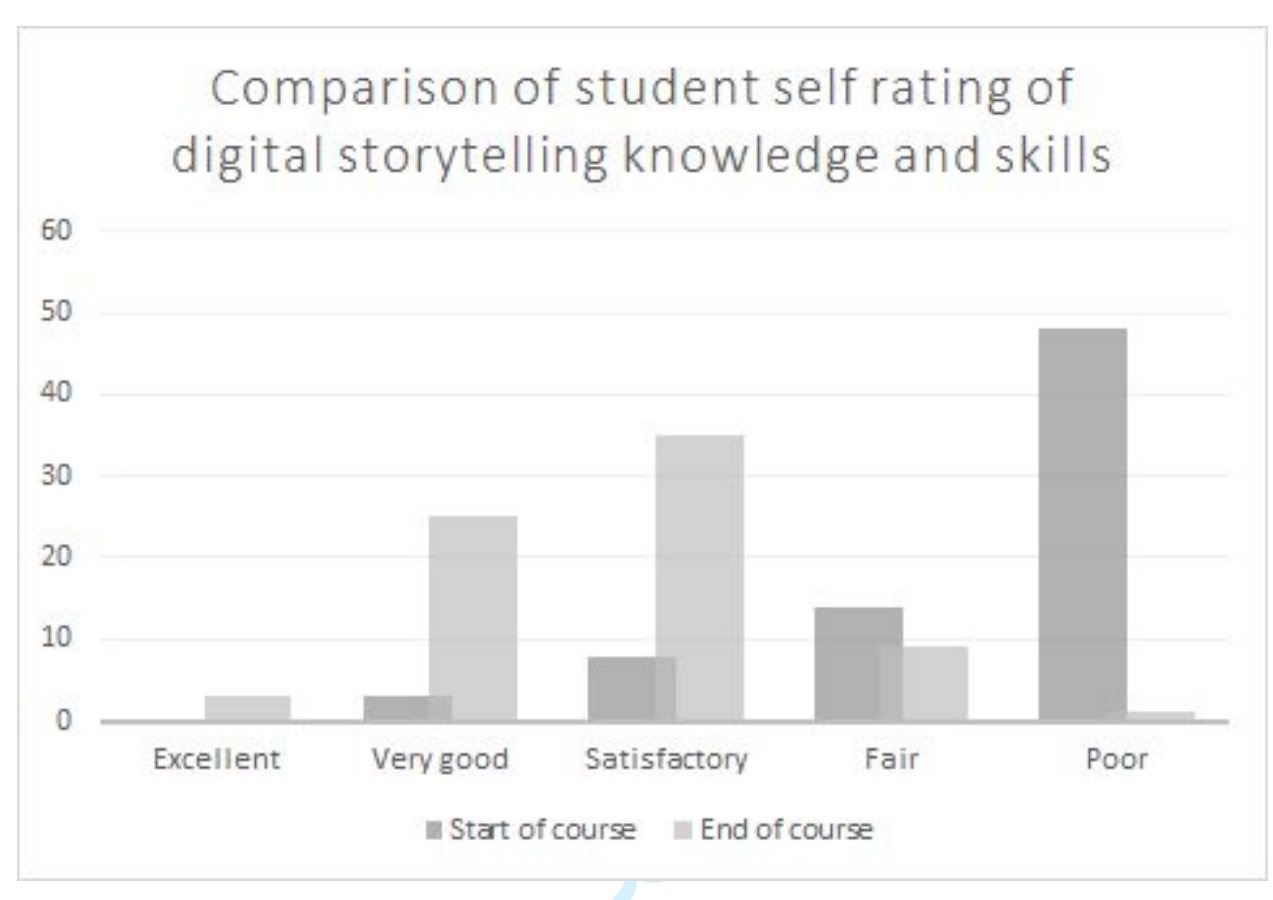


Figure 2 - Student perceptions of whether digital storytelling task was achievable compared with their self-rated knowledge and skill at the start of the course

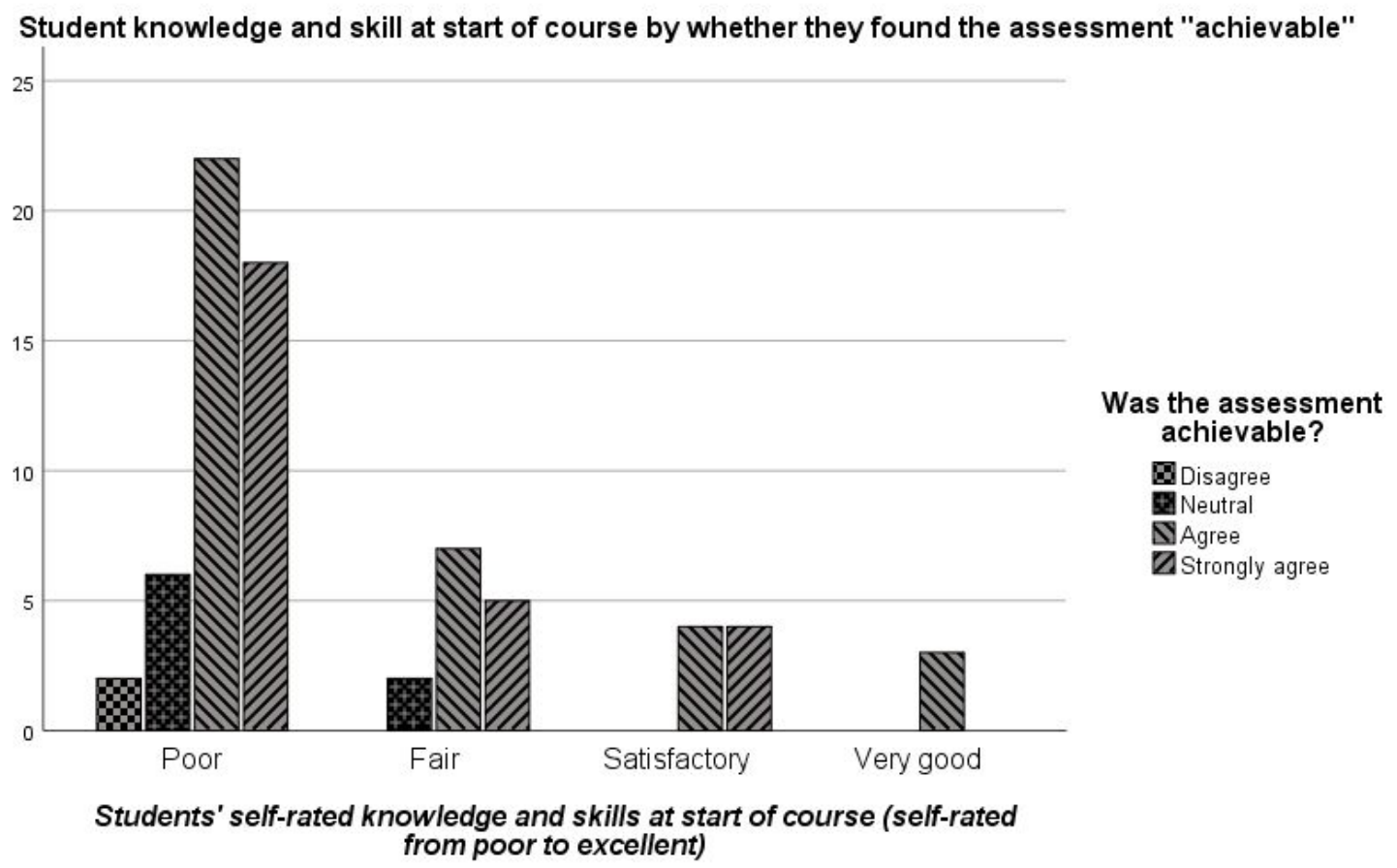


Figure 3 - Hierarchy chart of forms of support provided that students found helpful

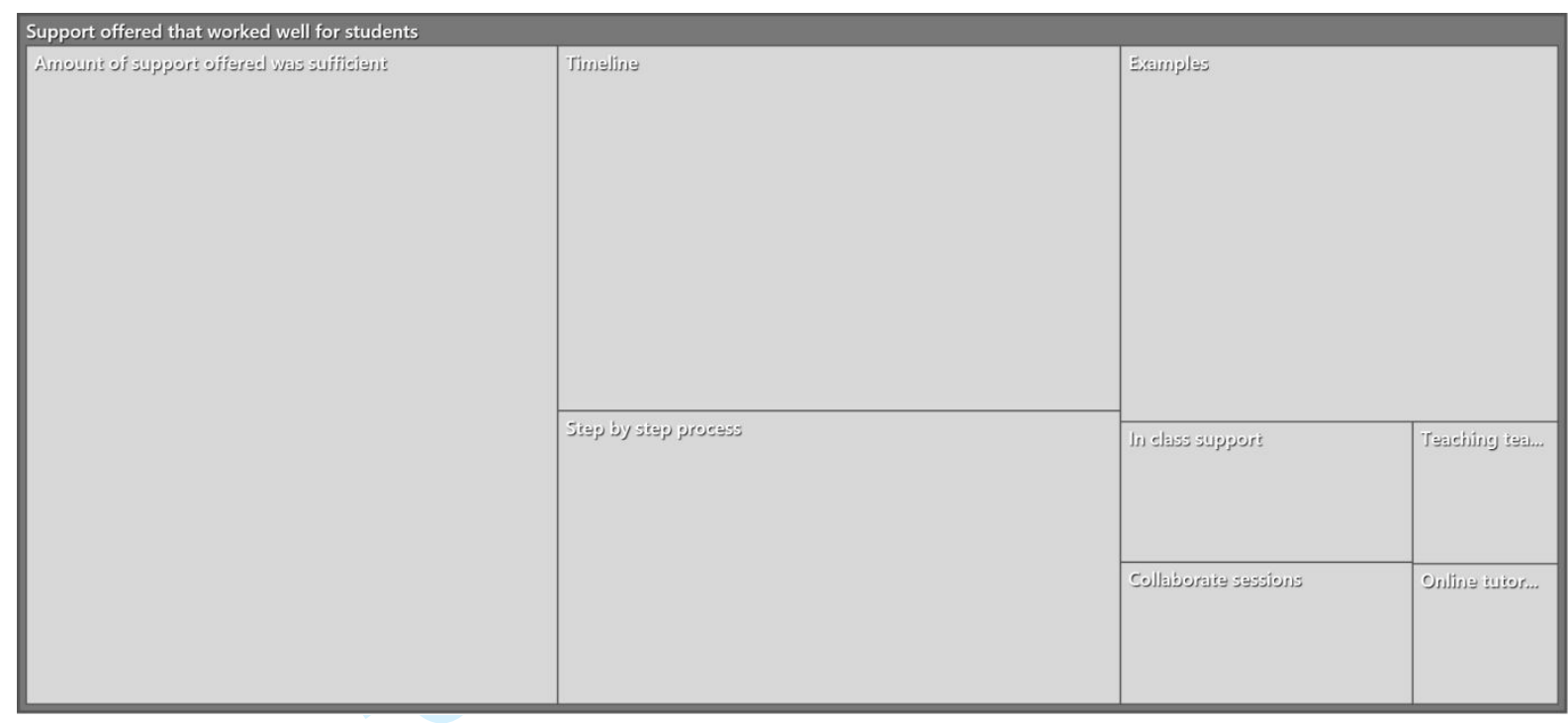


Figure 4: Hierarchy chart of student suggestions for additional support

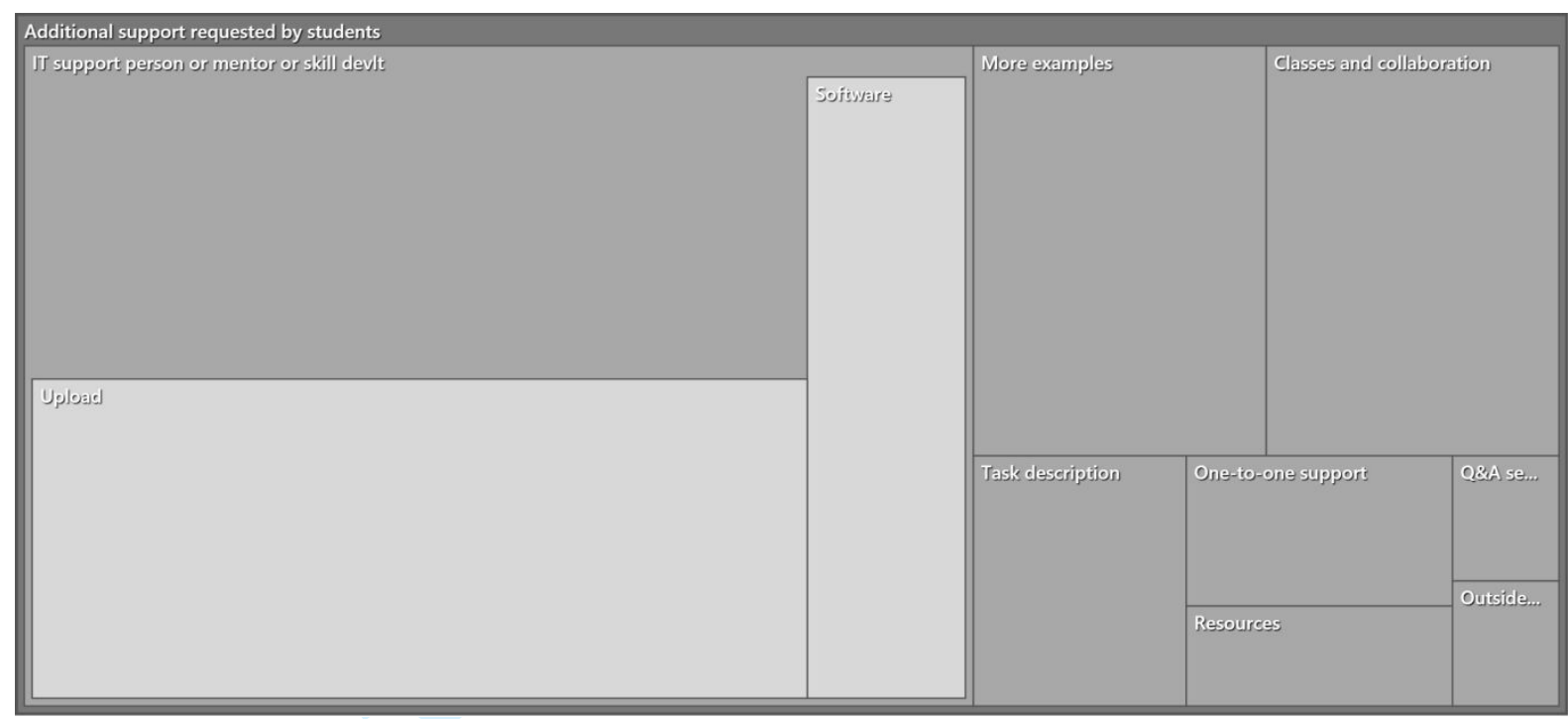




\section{List of Figures}

1. Comparison of student self-rating of digital storytelling knowledge and skills

2. Student perceptions of whether digital storytelling task was achievable compared with their self-rated knowledge and skill at the start of the course

3. Hierarchy chart of forms of support provided that students found helpful

4. Hierarchy chart of student suggestions for additional support 